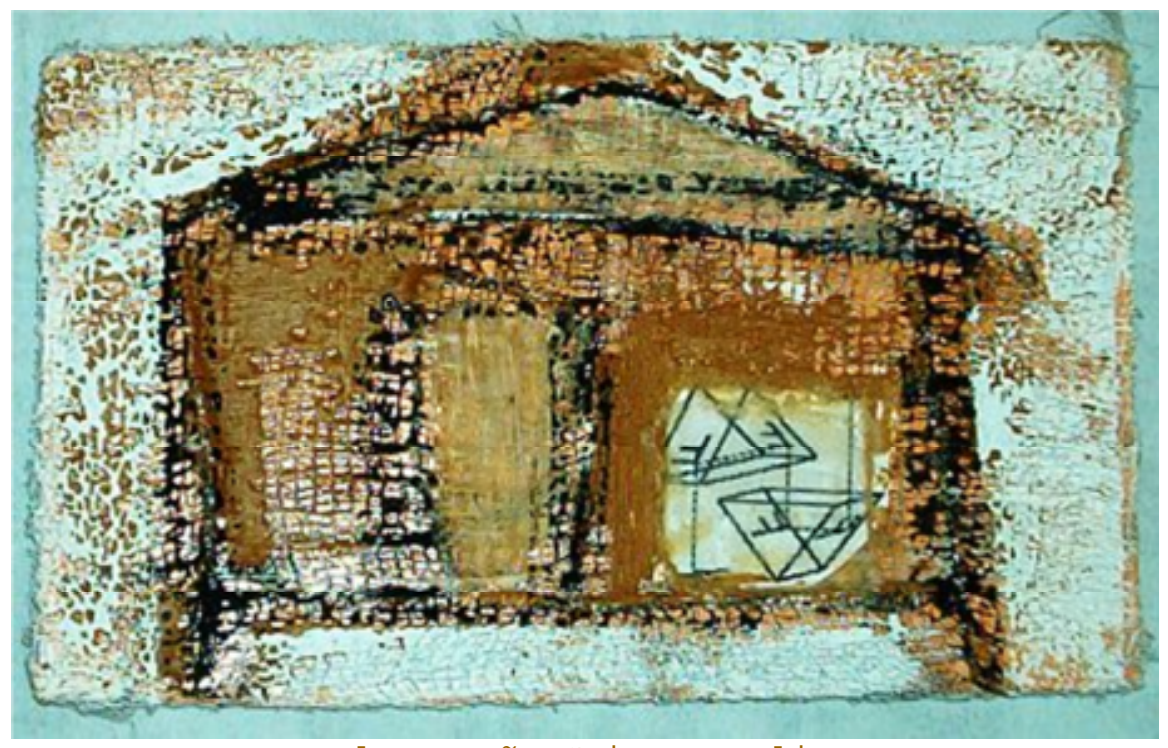

Ilustração Geisa Buzelin

\title{
A importância dos afetos familiares e escolares na formação do leitor
}

\section{Hércules Toledo Corrêa}

Hércules Toledo Corrêa é Doutor em Educação e professor da $U N I B H$.

\section{Resumo}

Este artigo procura discutir alguns aspectos de uma pesquisa mais ampla, intitulada "De leitores a escritores". São apresentadas e analisadas algumas situações de letramentos (apropriações e usos da escrita e da leitura) de leitores que vieram a se tornar escritores. Embasam teoricamente essa pesquisa conceitos dos estudos sobre os letramentos, que têm sido proficuamente desenvolvidos no Brasil, a sociologia da educação e das práticas culturais (principalmente através do pensamento de Pierre Bourdieu) e conceitos oriundos da teoria da literatura.

Palavras-chave: letramento, memórias, leitores. 


\section{I - Contextualização da pesquisa, objetivos e descrição do corpus}

Este artigo tem como objetivo recuperar algumas reflexões já feitas no âmbito da pesquisa "De leitores a escritores: o letramento literário em obras memorialísticas brasileiras do século XX" sobre as práticas de leitura e escrita em livros de memória: Explorações no tempo, de Cyro dos Anjos; Infância, de Graciliano Ramos; $O$ menino da mata e seu cão Piloto, de Vivaldi Moreira; Oito décadas, de Carolina Nabuco; e Meus verdes anos, de José Lins do Rego (1). Discutem-se e contrapõem-se as interações dos narradores com diferentes formas de manifestações literárias: cantigas de roda, contos tradicionais orais, poemas e romances de diferentes tipos, dentre outros. Apresentam-se, ainda, relatos das formas de aquisição da escrita pelos narradores, com suas facilidades e dificuldades, envolvendo-se, sempre, os afetos familiares e escolares. Nesta pesquisa, trata-se a literatura como um documento estetizado: ao mesmo tempo depoimento sobre uma época, uma vez que são textos de memória, e resultado de elaboração artística, já que se tem como corpus a obra literária. Não nos esquecemos, entretanto, do que nos aponta a teoria da literatura e a filosofia: a memória é uma forma de ficção, porque é uma representação. Bella Jozef chama a atenção para esse estatuto do texto autobiográfico: "tanto pode ser um discurso documental, testemunhal ou ficcional, fundando-se em convenções à primeira vista opostas: veracidade histórica e ficcionalidade interpretativa" (2). Dessa forma, são emergentes, hoje, estudos de áreas como História, Sociologia, Psicanálise, Psiquiatria, Filosofia, Pedagogia, dentre outras, que têm a literatura como corpus. Vale lembrar, ainda, que essa pesquisa se inscreve também no campo da História da Educação, já que as narrativas representam determinados momentos históricos do país (3).

A partir de espaços geográficos e de contextos familiares e sociais diferentes, mas de tempos próximos, pretende-se identificar as formas de letramento inicial de leitores que se tornaram, posteriormente, escritores. Podemos identificar, nas trajetórias dos escritores focalizados, a gênese de seus estilos, de suas formas de expressão. Cyro dos Anjos é um escritor prolixo, palavroso, denso em sua verborragia. Graciliano Ramos é seco, árido, lacônico, como a sua própria terra - o sertão brasileiro. Vivaldi Moreira também é prolixo. Detalhista em suas recordações, filosófico em muitas partes. Carolina Nabuco, na sua obra memorialística, apresenta um texto mais objetivo, direto, com pouco uso de recursos que poderíamos classificar como literários. No relato de suas oito décadas de vida, Carolina Nabuco está atenta a movimentos políticos e econômicos não só do Brasil como do mundo. José Lins do Rego, ao representar literariamente o ciclo da cana- 
de-açúcar e ao reconstruir a vida nos engenhos, tanto no seu livro de estréia, de 1932, Menino de engenho, assumido editorialmente como um romance, quanto em sua última obra, Meus verdes anos, de 1956, que traz em sua capa a indicação do gênero memórias, abaixo do título, apresenta o estilo claro e ao mesmo tempo poético da obra, relatando o que fora a sombria infância do menino Dedé, que sofria de "puxado" (regionalismo empregado para se referir à asma) e invejava os moleques da bagaceira, por não ter uma vida livre como a deles. Nota-se, em todas essas obras, cada qual a seu modo, grande preocupação e cuidado com a língua portuguesa, resultando produções esmeradas do ponto de vista lingüístico e literário.

Cyro dos Anjos pode ser considerado um herdeiro da cultura erudita: filho de pais cultos, sobrinho e primo de filósofos, (4) desde criança conviveu com pessoas letradas na pequena Montes Claros. Já Graciliano Ramos desde muito cedo conviveu com homens rudes e grosseiros: o pai severo, para quem a maior importância dos livros estava no de contas-correntes (5) ; vaqueiros, colonos, professores mal preparados. Em um ambiente agreste, em meio à pobreza do sertão nordestino, o menino Graciliano aprende as primeiras letras, com o pai e em escolas rurais. Graciliano Ramos traz, em seu texto, a marca da amargura. Cyro dos Anjos, ao contrário, tendo sido criado em meio a serões culturais e artísticos, traz a marca de um universo lírico, carregado de poesia.

Vivaldi Moreira, nascido em uma família de origem rural mineira, tem pai e mãe que valorizam a leitura e a formação escolar: seu pai assinava jornais cariocas, que chegavam semanalmente à Fazenda do Tanque - como o Correio da manhã e 0 jornal, de Assis Chateaubriand; a mãe recebia a revista Vida doméstica, com as novidades da cultura européia; para o menino Vivaldi o pai assinava a famosa revista infantil Tico-Tico. Vivaldi Moreira também pode ser considerado um herdeiro cultural.

Carolina Nabuco, filha do estadista e abolicionista Joaquim Nabuco, embora teça comentários sobre uma certa falta de dinheiro no seio familiar, dos cinco escritores aqui tratados, muito provavelmente é a que maior herança cultural recebeu de sua família. Seu pai é autor de uma das mais importantes obras memorialísticas em língua portuguesa, Minha formação, conforme argumenta Afonso Henrique Fávero (1999), em trabalho sobre o gênero memória na literatura brasileira. Carolina Nabuco declara que, antes dos nove anos, já falava fluentemente o francês, o que lhe proporcionava a leitura, já nessa idade, em duas línguas. Ainda criança, mora, com a família, na França, na Inglaterra e nos Estados Unidos, o que lhe proporciona uma educação em países desenvolvidos. 
O paraibano José Lins do Rego, cuja mãe morrera no parto, foi criado pelo avô materno, e começou a aprender as primeiras letras em casa. Posteriormente, freqüentou as salas de aula de mestres-escola de seu tempo: Dr. Figueiredo, D. Donzinha, Dr. João Cabral, Sinhá Gorda e sua irmã Maria Luísa. Também teve as dificuldades com as quais se deparara o também nordestino e posterior amigo Graciliano Ramos. O processo de alfabetização de José Lins do Rego foi árduo. O narrador se sentia incapaz, sofria com as comparações familiares dos agregados e exescravos do engenho, até "desasnar-se".

\section{II - As experiências dos memorialistas em seus processos de letramentos}

Explorações no tempo, de Cyro dos Anjos, foi publicado em 1963. O texto revisto passou a constituir a primeira parte do livro A menina do sobrado, com o título de "Santana do Rio Verde", em 1979. É possível identificar na prosa do memorialista mineiro a mediação de diversas instituições e de diferentes sujeitos na formação do leitor, tais como a família (principalmente nas figuras do pai, do primo e da velha empregada); a escola (na figura das professoras primárias); 0 tio filósofo e seus livros; as leituras de romances de capa-eespada na adolescência; as discussões literárias com os amigos de boemia da Belo Horizonte dos anos vinte, dentre eles o conterrâneo Newton Prates, jornalista, e os escritores Carlos Drummond, Emílio Moura e Pedro Nava, dentre vários outros como mostra a parte "Mocidade, amores", de A menina do sobrado (6) .

As primeiras referências ao contato com a literatura, na obra de Cyro dos Anjos, são encontradas nos primeiros capítulos do livro: as histórias da Carochinha, contadas pelo primo Ataualpa, e os casos populares da empregada da família, Luísa Velha. Com relação ao estímulo escolar, o narrador rememora o incentivo literário advindo de um dos professores, que o presenteara com uma edição infantil de os Lusíadas. No início de sua vida escolar, o menino já demonstrava aptidão para a escrita de poemas e notícias publicadas em jornais manuscritos (7) .

- livro de memórias Infância, de Graciliano Ramos, publicado em 1945, também apresenta uma série de referências ao processo de letramento de seu narrador. A obra traz, inclusive, dois capitulos intitulados "Leitura" e "Escola", além de vários outros com nomes ou referências a professores. Diferentemente do narrador de Explorações no tempo, o narrador de Infância teve, inicialmente, uma relação complicada com a alfabetização e com a leitura, não tendo tido, em seu meio familiar, motivações que o tornassem, num primeiro momento, um leitor: a incapacidade e a falta de didática do pai ao tentar 
alfabetizá-lo, no capítulo "Leitura", levam o narrador a afirmar por duas vezes, no capítulo "Os astrônomos", que aos nove anos ainda não sabia ler e escrever (8). As dificuldades de leitura do menino Graciliano podem ser ilustradas pela conhecida passagem do capítulo "Leitura", em que o narrador, ao se deparar com a forma mesoclítica "ter-te-ão", no provérbio "Fala pouco e bem: ter-te-ão por alguém", pensa se referir a um homem: o senhor Terteão (9).

Imagens vão e vêm na mente, tanto na do narrador quanto na do leitor do primeiro capítulo de Infância, que recebeu o sugestivo título de "Nuvens". Essas imagens tematizam o universo rural: um vaso de pitombas, açudes, abóboras, vaqueiros, sinhás; em meio a elas, a imagem de uma sala de aula, com alunos que soletravam: "- Um b com um a - b, a: ba; um $\mathrm{b}$ com um e - b, e: be.". "Um velho de barbas longas dominava uma mesa negra" : assim o narrador via o professor numa sala repleta de meninos sentados em bancos sem encosto a "esgoelar" a soletração. "A escola servira de pouso numa viagem" do interior das Alagoas para o sertão de Pernambuco, para onde a família migrava (10). Em meio a condições adversas, - menino se lembra das lições do velho professor, da irmã natural na sala de aula e do colono José Baía e seus versos populares. Também significativa é a lembrança da mãe, que lia romances, mesmo com dificuldade, gaguejando, e recitava partes deles ao embalar o filho na rede (11).

A despeito da malograda experiência de alfabetização, realizada pelo pai, aparecem na vida do narrador personagens que começam a proporcionar-lhe a aproximação com os livros. No capítulo "Samuel Smiles", menciona as histórias contadas pela professora Agnelina: "Essa professora atrasada possuía raro talento para narrar histórias de Trancoso. Visitava-nos, prendia-nos até meia-noite com lendas e romances, que estirava e coloria admiravelmente. Nada me ensinou, mas transmitiu-me afeição às mentiras impressas" (12). Márcia Cabral da Silva (13) compara a descoberta da leitura, para Graciliano Ramos, a um "terrível rito de passagem", no qual o tabelião Jerônino Barreto torna-se uma figura importantissima, uma vez que tal personagem, leitor contumaz, disponibilizava para o narrador sua biblioteca pessoal.

Em seu artigo, Márcia Cabral da Silva ainda trata de um dado interessante: nem sempre os mediadores de leitura estarão enraizados nos meios familiares e nas instituições escolares. Duas das obras aqui analisadas apontam para isso: a despeito das experiências de leitura na infância de Cyro dos Anjos, no seio familiar e na instância escolar, sem dúvida as rodas literárias freqüentadas pelo jovem escritor e jornalista na Belo Horizonte modernista, nos anos 20, contribuíram peremptoriamente para a formação do leitor e do escritor. A 
experiência de Graciliano é bem diferente: ambiente adverso, pouca convivência com pessoas letradas na infância, mas ressalta-se a mediação de Jerônimo Barreto, na sua formação de leitor, antes de seus vôos literários. No encontro com o segundo livro de leitura, do Barão de Macaúbas, com seus apólogos, o menino Graciliano, aos sete anos, conheceu e odiou Camões e Os Lusíadas: associou, com ódio, o Barão de Macaúbas ao mestre português.

Vivadi Moreira, escritor e advogado, presidente da Academia Mineira de Letras por muitos anos, publicou o menino da mata e seu cão Piloto em 1981. Em suas memórias, o autor traça um painel de sua existência, começando pela infância na Fazenda do Tanque, propriedade de sua avó materna, subdividida entre seus tantos filhos, dentre eles seu Pedro Moreira, pai do narrador, fazendeiro e comerciante que viu seus negócios se arruinarem em 1929, reflexo longínquo do crack da bolsa de Nova Iorque. Ainda que com professores medíocres no aprendizado das primeiras letras, como o guarda-livros do pai, - senhor Bernardino de Morais (14), o menino Vivaldi encantouse com o Novo terceiro livro de leituras, de Hilário Ribeiro. Através das páginas desse livro, que considera ter aberto as portas do mundo para ele (15), "viajou" pela Europa: conheceu Paris, Gênova e Veneza, dentre outras. Vivaldi menciona também a existência de um caderno de leitura, onde anotava, desde 1933, os livros que lia (16).

Oito décadas é o livro de memórias da biógrafa e ficcionista Carolina Nabuco, publicado na década de 70. No primeiro capítulo, a narradora descreve a aprendizagem das primeiras letras, ainda com cinco anos, sentada ao lado da mãe na carteira de colegial que ganhara, como algo extremamente prazeroso (17). A menina, bisneta e neta de barões, pelo lado materno, e filha do conhecido estadista e monarquista Joaquim Nabuco, desde cedo demonstrou tendência para as letras. Sua mãe, que tinha o francês como segunda língua, ensinou-lhe o idioma, que a menina dominava aos nove anos, como declara (18) no capítulo intitulado "1890-1900", a primeira das oito décadas de sua vida. Das recordações dos presentes de infância, a que mais está viva em sua memória é o dia em que o pai lhe trouxe, de uma só vez, quatro livros da Condessa de Ségur, em francês. A menina tornou-se grande leitora da Bibliothéque Rose em suas versões originais.

Carolina Nabuco tornou-se muito conhecida do grande público brasileiro por ter escrito a biografia de seu pai, no final da década de 1920, A vida de Joaquim Nabuco, ao qual ela se referia sempre como "meu livro", e pelo romance A sucessora, publicado na década de 30. Algum tempo depois, a inglesa Daphne du Maurier publicaria Rebecca, com personagens e enredo muito semelhantes ao livro de Carolina Nabuco, o que aumentou 
ainda mais a popularidade da escritora brasileira. O famoso crítico Álvaro Lins publicou um rodapé literário no Correio da Manhã comparando os dois livros e concluindo que realmente se tratou de um plágio.

- crítico literário Antônio Carlos Villaça, no prefácio de Meus verdes anos, relembra as palavras de Brito Broca, que em texto publicado no Correio da Manhã de 7 de julho de 1956, já trazia a questão das relações entre autobiografia e obra ficcional, lembrando os escritores André Gide e Visconde de Taunay. São feitas várias comparações entre o enredo e as personagens de Menino de engenho e de Meus verdes anos, mostrando-se, por exemplo, como a morte no parto da mãe do escritor José Lins foi representada literariamente através do assassinato da mãe do protagonista Carlinhos pelo marido, em um acesso de loucura. O menino vai ser criado pelo avô materno, senhor de engenho, em meio às tias e aos criados da fazenda. Brito Broca observa, ainda, que a infância de que o escritor queria libertar-se catarticamente com a produção do ficcional Menino de engenho continuou a atormentá-lo até que o escritor expiasse seus traumas com o memorialístico Meus verdes anos. O processo doloroso de aquisição da escrita do menino Dedé é descrito, principalmente, nos capítulos 30 e 33 de Meus verdes anos. Inicialmente, são relatadas as experiências malogradas com Dr. Figueiredo, que chegou a gritar no ouvido do aprendiz: "- Menino burro!" e "Nunca vi menino mais rude." (19), e acabou por dar-lhe com uma régua na cabeça, deixando-lhe um enorme galo na testa. Entra em cena, então, a Dona Donzinha, professora diplomada, com anel no dedo, e que podia até ensinar francês, se quisesse (20). Posteriormente, vem a escola de João Cabral, para meninos, onde o menino Dedé gozava de certas regalias. Enquanto os outros moleques sentavam-se em toscos bancos de madeira, para - neto do senhor de engenho viera especialmente da fazenda uma cadeira de palhinha (21). Então, o menino é encaminhado para as aulas particulares de sinhá Gorda, auxiliada pela irmã (magricela) Maria Luísa, que por fim o alfabetiza: "enfim, como relata a tia Naninha: Sinhá gorda conseguiu desasnar o José (22)."

No capítulo 31 (23), o narrador de Meus verdes anos relata os produtivos encontros com a velha Totônia. Em 1936, José Lins do Rego rende à contadora de histórias de Trancoso uma homenagem, ao publicar as suas Histórias da Velha Totônia, o que lhe garantiu a incursão na então incipiente literatura para crianças no Brasil.

\section{III - Heranças culturais dos memorialistas}

Para muitos sociólogos da educação, na esteira dos estudos desenvolvidos por Pierre Bourdieu, a distinção de classe não 
se liga somente à questão econômica, mas também à questão cultural. De acordo com esses pesquisadores, além de um capital econômico, existem ainda os capitais sociais e culturais, este último possível de ser herdado pelos descendentes das famílias detentoras dele à semelhança de um bem material - capital econômico. Dessa forma, Bourdieu e seus seguidores relacionam e condicionam o sucesso escolar à herança cultural. Aqui, não tratamos de sucesso escolar, mas procuramos pensar a formação do escritor a partir de sua formação de leitor, um sujeito imerso em um ambiente sociocultural. Bourdieu tem sido criticado, principalmente, devido a um certo determinismo de suas teorias (24). As conclusões, embora provisórias, de nossas pesquisas também nos levam a identificar sujeitos que se sobressaíram à revelia de suas parcas heranças culturais (pelo menos em se tratando de cultura erudita), ao lado de sujeitos que souberam aproveitar a herança que receberam, apropriando-se muito bem dela.

Em Explorações no tempo, podemos considerar o narrador um legítimo herdeiro cultural, cujo gosto pela leitura foi sendo apropriado pelo menino, a despeito do enfado sentido nos serões de leitura do pai. Filho de uma família de classe média: seu pai era comerciante e fazendeiro, culto, convivia com juízes, promotores e poetas da cidade; era grande leitor de ensaios filosóficos e literários; também conhecia o latim; a mãe era versada em francês e latim, a família de Cyro dos Anjos pode ser classificada como detentora de um bom capital cultural. A família Versiani dos Anjos, dentre seus treze filhos, teve também como escritores o médico Valdemar Versiani dos Anjos e o farmacêutico Antônio Versiani dos Anjos, filhos do mesmo Antônio dos Anjos e de Dona Carlota Versiani dos Anjos.

Um dos mais representativos escritores da literatura brasileira, "o velho Graça" - como é carinhosamente referido é o filho primogênito de dezesseis que teriam seus pais, Sebastião Ramos de Oliveira e Maria Amélia Ferro Ramos. Graciliano viveu sua infância nas cidades de Viçosa e Palmeira dos Índios ( $\mathrm{AL}$ ) e Buíque (PE), sob o regime das secas e das surras que lhe eram aplicadas por seu pai, que o fizeram alimentar, desde cedo, a idéia de que todas as relações humanas eram regidas pela violência. Em termos de capital cultural erudito - e provavelmente também econômico -, a família de Graciliano era bem inferior à de Cyro. Ambos os pais eram pequenos comerciantes, em cidades do interior brasileiro, mas embora tivessem a mesma profissão, eram homens bem diferentes. O pai do narrador de Explorações no tempo era um homem que valorizava a cultura erudita, tinha no seu "círculo da loja" amigos importantes. Já o pai do narrador de Infância, embora também tenha alcançado certos êxitos, como o 
de tornar-se juiz substituto (ver capitulo "Venta-Romba"), era um sujeito rude, de poucas letras.

Vivaldi Moreira, descendente de um comerciante leitor, como Cyro dos Anjos, também herda de sua família e de seu círculo de amigos o amor pelas letras. Com uma trajetória de vida marcada por leituras filosóficas e literárias, Vivaldi Moreira pode ser considerado um "homem dos livros".

Dentre os escritores aqui analisados, Carolina Nabuco parece ser a maior herdeira de uma cultura erudita, letrada, conforme já se apontou. Suas longas estadas no exterior desde menina, sua educação européia - com o domínio pleno do francês e do inglês, além, obviamente, do português, sua língua materna -, sua ascendência nobre, seu pai famoso como estadista e abolicionista, sua mãe requintada e erudita, legaram-lhe, como uma herança legítima, uma vasta cultura, representada por uma produção escrita que abarcou, além do mencionado romance $A$ sucessora e da biografia do seu pai, páginas de crítica sobre a literatura norte-americana, as biografias de Virgílio de Mello Franco e de Santa Catarina de Sena, o romance Chama e cinzas, dentre outros.

Os escritores nordestinos Graciliano Ramos e José Lins do Rego não podem ser considerados herdeiros de uma cultura erudita. A leitura de Infância e de Meus verdes anos aponta claramente para isso. Curiosamente - ou ironicamente -, foram eles que alcançaram, até o presente momento, melhores posições no cânone literário brasileiro, contrariando o que se poderia prever pela teoria sociológica de Bourdieu. Entretanto, é importante lembrar que das obras aqui tratadas, Infância é a que mais se aproxima de uma ficcionalização da memória. Antonio Candido já tratou muito bem dessa questão em Ficção e confissão (CANDIDO, 1992). Menino de engenho e Meus verdes anos são exemplos claros da inexistência de limites muito bem demarcados entre ficção e confissão, como já se apontou. Explorações no tempo, o menino da mata e seu cão Piloto e Oito décadas, através de algumas pistas textuais - como nomes completos de familiares, localizações temporais e espaciais mais específicas - propõem ao leitor um pacto autobiográfico, como chamou Phillippe Lejeune (25), muito maior que Infância, que proporciona, ambiguamente, um pacto ficcional mesclado a um pacto autobiográfico, ou como também se pode pensar para Menino de engenho.

Pode-se concluir que as trajetórias dos narradores, dentre outros fatores aqui não-considerados, devido aos objetivos e às limitações da análise, levaram à formação de escritores com características bem distintas, como já se apontou. Contribuições familiares - não só os pais, mas também tios, irmãos mais velhos, agregados e círculos de amigos - e 
escolares - os mestres-escola, os professores particulares -, às vezes de forma tosca e desestimulante, outras de forma carinhosa e afetiva, contribuem para a formação desses sujeitos e a constituição de suas identidades. Essas obras autobiográficas/memorialísticas, com suas diferenças e especificidades, merecem a atenção de pesquisadores que procuram reunir, hoje, literatura e educação, buscando compreender a formação do leitor, em seus aspectos mais amplos, por meio dos letramentos funcional, literário, filosófico, científico etc. e de suas relações com a formação de um intelectual da palavra - a figura do escritor.

\section{Abstract}

This text aims at discussing some aspects of a larger research entitled "From readers to writers". An analysis of some practices of literacies of readers who became writers will be conducted. The research is theoretically framed by studies of literacies that are being adopted and developed in Brazil, but also by concepts from sociology of education and of cultural practices (mainly through Pierre Bourdieu works) as well as literary theory.

Key-words: literacy, literary memories, readers.

\section{Notas}

(1) Todas as referências às obras foram feitas a partir das seguintes edições: 1) ANJos, Cyro dos. Explorações no tempo (memórias). Rio de Janeiro: José Olympio, 1963. 2) RAMOS, Graciliano. Infância. 25. ed. Rio de Janeiro: Record, 1993. 3) MOREIRA, Vivaldi Moreira. O menino da mata e seu cão Piloto. Belo Horizonte: Imprensa Oficial, 1981. 4) NABUCO, Carolina. Oito décadas. 2. ed. Rio de Janeiro: Nova Fronteira, 2000. 5) REGO, José Lins do. Meus verdes anos. 7. ed. Rio de Janeiro: José Olympio, 2002.

(2) JOZEF, 1997, p.217.

(3) Ver, por exemplo, as referências bibliográficas: ABRAHÃO (2004), AGUIAR (1997) e RIEDEL (1988).

(4) O Tio Tatá - Major Artur Versiani de Oliveira, irmão da mãe de Cyro dos Anjos, p. 74-81, e o primo Artur, filho do Tio Veloso, p. 232-237).

(5) p. 48 .

(6) WERNECK (1992) faz uma análise dessas "rodas literárias" da Belo Horizonte da primeira metade do século XX no livro o desatino da da rapaziada: jornalistas e escritores em Minas Gerais. (7) p. 60.

(8) p. 187 e 188

(9) p. 99 .

(10) p. 8 e 9 . 

(11) p. 13-14 e p.63.
(12) p. 194
(13) SILVA, 2001
(14) p. 54 e 78
(15) p. 52.
(16) p.59.
(17) p. 14.
(18) p. 15 .
(19) p. 129.
(20) p. 130.
(21) p. 141-142.
(22) p. 146 .
(23) p. 135-137.
(24) LAHIRE, 1997.
(25) LEJEUNE, 1975.

\section{Bibliografia}

ABRAHÃo, Maria Helena Menna Barreto. (Org.) A aventura (auto)biográfica. Teoria \& empiria. Porto Alegre: EDIPUCRS, 2004.

AGUIAR, Flávio et al. Gêneros de fronteira. Cruzamentos entre o histórico e ○ literário. São Paulo: Xamã, 1997.

Anjos, Cyro dos. Explorações no tempo. (Memórias) Rio de Janeiro: José Olympio, 1963.

BOURDIEU, Pierre. Escritos de educação. 2. ed. Petrópolis: Vozes, 1999.

CABRAL DA SILVA, Márcia. Infância, de Graciliano Ramos: uma história da formação do leitor no Brasil. Campinas: IEL/UNICAMP, 2004. (tese de doutorado)

CANDIDO, Antonio. Ficção e confissão: ensaios sobre Graciliano Ramos. Rio de Janeiro: Editora 34, 1992.

CORRÊA, Hércules Tolêdo. Formação do leitor literário em livros de memórias. Anais do 40 Encontro de Literatura Infantil e Juvenil. Rio de Janeiro: UFRJ, 2005. 
CORRÊA, Hércules Tolêdo e RIBEIRO, Georgia Roberta de Oliveira. Relações entre o letramento literário e a formação do escritor em $A$ menina do sobrado, de Cyro dos Anjos. PAIVA, Aparecida et al. (Orgs.) Democratizando a leitura: pesquisas e práticas. Belo Horizonte: Autêntica, 2004. p. 121134

CORRÊA, Hércules Tolêdo. E o leitor se tornou um escritor: relações entre letramento literário e a formação do escritor em A menina do sobrado, de Cyro dos Anjos. Revista do Centro de Estudos Portugueses. Belo Horizonte: FALE/UFMG, n. 33, jan-dez. 2004a. p. 235-252. ISSN 1676-515X

CORRÊA, Hércules Tolêdo. Letramento literário: de leitores a escritores. Revista Estudos. Belo Horizonte: UNI-BH, v. 2, n. 2, setembro de 2004b. p. 25-42. ISSN 1678-2453

CORRÊA, Hércules Tolêdo. Relações entre o letramento literário e a formação do escritor em A menina do sobrado, de Cyro dos Anjos. Anais do Terceiro Simpósio Internacional do Centro de Estudos de Narratologia. Buenos Aires. Julho de $2004 \mathrm{c}$.

DE SINGLY, François. L'appropriation de l'héritage culturel. Lien social et politiques, n. 35, p. 153-154, printemps 1996.

LAHIRE, Bernard. Sucesso escolar nos meios populares: as razões do improvável. São Paulo: Ática, 1997.

LEJEUNE, Phillippe. Le pacte autobiographique. Paris: Éditions du Seuil, s/d. 357 p. (Copyright de 1975)

MOREIRA, Vivaldi. O menino da mata e seu cão Piloto. Belo Horizonte: Imprensa Oficial, 1981.

NABUCO, Carolina. Oito décadas. 2. ed. Rio de Janeiro: Nova Fronteira, 2000 .

OLIVEIRA, Maria Helena Palma de. Lembranças do passado: a infância e a adolescência na vida de escritores brasileiros. São Paulo: Universidade São Franscisco, 2001 .

PESSANHA, José Américo Motta. História e ficção: o sono e a vigília. In: RIEDEL, Dirce Côrtes. (Org.) Narrativa: fiç̧ão \& história. Imago, $1988 . p$. 282-299.

RAMos, Graciliano. Infância. 25. ed. Rio de Janeiro: Record, 1993.

RIEDEL, Dirce Côrtes. (Org.) Narrativa: fiç̧ão \& história. Imago, 1988. REGO, José Lins do. Meus verdes anos. 7a ed. Rio de Janeiro: José Olympio, 2002 .

REGo, José Lins do. Menino de engenho. $48 \mathrm{a}$ ed. Rio de Janeiro: José Olympio, 1991. 